\title{
Effects of Medicaid Drug-Payment Limits on Admission to Hospitals and Nursing Homes
}

\section{Citation}

Soumerai, Stephen B., Dennis Ross-Degnan, Jerry Avorn, Thomas J. McLaughlin, and Igor Choodnovskiy. 1991. "Effects of Medicaid Drug-Payment Limits on Admission to Hospitals and Nursing Homes." New England Journal of Medicine 325 (15) (October 10): 1072-1077. doi:10.1056/nejm199110103251505.

\section{Published Version}

doi:10.1056/NEJM199110103251505

\section{Permanent link}

http://nrs.harvard.edu/urn-3:HUL.InstRepos:32696157

\section{Terms of Use}

This article was downloaded from Harvard University's DASH repository, and is made available under the terms and conditions applicable to Other Posted Material, as set forth at http:// nrs.harvard.edu/urn-3:HUL.InstRepos:dash.current.terms-of-use\#LAA

\section{Share Your Story}

The Harvard community has made this article openly available.

Please share how this access benefits you. Submit a story.

\section{Accessibility}




\title{
SPECIAL ARTICLE
}

\section{EFFECTS OF MEDICAID DRUG-PAYMENT LIMITS ON ADMISSION TO HOSPITALS AND NURSING HOMES}

\author{
Stephen B. Soumerai, Sc.D., Dennis Ross-Degnan, Sa.D., Jerry Avorn, M.D., \\ Thomas J. MaLaughlin, Sc.D., and Igor Ghoodnovskiy, B.S.
}

\begin{abstract}
Background. Many state Medicaid programs limit the number of reimbursable medications that a patient can receive. We hypothesized that such limitations may lead to exacerbations of illness or to admissions to institutions where there are no caps on drug reimbursements.

Methods. We analyzed 36 months of Medicaid claims data from New Hampshire, which had a three-drug limit per patient for 11 of those months, and from New Jersey, which did not. The study patients in New Hampshire $(n=411)$ and a matched comparison cohort in New Jersey $(n=1375)$ were Medicaid recipients 60 years of age or older who in a base-line year had been taking three or more medications per month, including at least one maintenance drug for certain chronic diseases. Survival (defined as remaining in the community) and time-series analyses were conducted to determine the effect of the reimbursement cap on admissions to hospitals and nursing homes.
\end{abstract}

Results. The base-line demographic characteristics of the cohorts were nearly identical. In New Hampshire,

$\mathrm{C}$ YONCERN has mounted that cost-containment 1 policies implemented during the 1980 s may be compromising the quality of care and the health of vulnerable populations, such as poor and chronically ill elderly peop'e, although few studies have examined this question.,$\because$ Charges to the patient or monthly limits on medications and other "optional" services are characteristic of most Medicaid programs. ${ }^{3}$ Although such restrictions on specific services could increase admissions to hospitals and nursing homes among chronically ill elderly people, this has not been demonstrated in a controlled study. Decades of clinical research and experience document the effectiveness of many medications in treating both acute life-threatening illnesses and chronic debilitating conditions. ${ }^{4-6}$ Lack of compliance with drug therapy has been associated with increased admissions to hospitals and nursing homes. ${ }^{7-10}$ Logically, then, policies that reduce access to effective medications may increase the rate of adverse clinical outcomes and the accompanying costs.

In an earlier study ${ }^{11}$ we examined the effects of a three-drug payment limit, or cap, on the use of med-

From the Department of Social Medicine, Harvard Medical School (S.B.S., D.R.-D., T.J.M.), and the Program for the Analysis of Clinical Strategies and the Department of Medicine, Harvard Medical School and Beth Israel Hospital (J.A., I.C.), Boston. Address reprint requests to Dr. Soumerai at the Department of Social Medicine, Harvard Medical School, 643 Huntington Ave., Boston, MA 02115.

Supported by grants from the Agency for Health Care Policy and Research, Department of Health and Human Services (HSO5947), the John A. Hartford Foundation, and the National Institute on Aging.

Presented in abstract form at the annual meeting of the Association for Health Services Research, Washington, D.C., June 19, 1990. the 35 percent decline in the use of study drugs after the cap was applied was associated with an increase in rates of admission to nursing homes; no changes were observed in the comparison cohort $(R R=1.8 ; 95$ percent confidence interval, 1.2 to 2.6 ). There was no significantly increased risk of hospitalization. Among the patients in New Hampshire who regularly took three or more study medications at base line, the relative risk of admission to a nursing home during the period of the cap was 2.2 (95 percent confidence interval, 1.2 to 4.1 ), and the risk of hospitalization was 1.2 (95 percent confidence interval, 0.8 to 1.6). When the cap was discontinued after 11 months, the use of medications returned nearly to base-line levels, and the excess risk of admission to a nursing home ceased. In general, the patients who were admitted to nursing homes did not return to the community.

Conclusions. Limiting reimbursement for effective drugs puts frail, low-income, elderly patients at increased risk of institutionalization in nursing homes and may increase Medicaid costs. (N Engl J Med 1991;325:1072-7.)

ications among 10,734 Medicaid patients in New Hampshire. Among 860 recipients of three or more drugs, the cap was associated with significant reductions in the receipt of several important medications (e.g., 28 to 30 percent reductions for insulin, thiazides, and furosemide) that were not offset by increased outof-pocket purchases. When a copayment of $\$ 1$ per prescription replaced the cap one year later, the use of most agents quickly approached precap rates.

In that study, data were not available to measure possible changes in use of institutional services. One hypothesized effect of the cap was an increase in nursing home admissions, due either to deteriorating health or to a desire to shift to an environment exempt from the cap. If the loss of essential medications led to an acute deterioration in health, one might also expect increased hospital admissions. In the current study, we analyzed 36 months of additional nondrug claims and enrollment data from Medicaid to answer the following question: Among low-income, elderly Medicaid patients, is limiting access to medications associated with increased rates of admission to nursing homes and hospitals?

\section{Methods}

\section{Study Design}

This study used survival (defined as remaining in the community) and interrupted time-series analyses to evaluate the effects of the drug-payment restriction. Outcome data included 36 months (July 1980 to June 1983) of patients' nursing home and hospital inpatient claims in two state Medicaid programs. We compared the rate of admission to nursing homes and hospitals before, during, and after the cap in a defined cohort of chronically ill elderly patients in the 
study state (New Hampshire) with the rate in an identically defined comparison cohort in a state without a cap (New Jersey).

The three-drug payment limit implemented by New Hampshire Medicaid during months 15 to 25 of the 36 -month study period is described in detail in our previous report. ${ }^{11}$ With less than two months' notice to providers and patients, the legislatively mandated cost-containment measure restricted most Medicaid patients to three prescriptions per month. After 11 months the cap was eliminated and replaced with a copayment of $\$ 1$ per prescription. The comparison state, New Jersey, was the only northeastern state whose Medicaid program had no cost-sharing requirements or payment limitations for drugs during the study period.

\section{Availability and Quality of Data}

Data on enrollment, the use of study drugs, and hospital and nursing home admissions came from the computerized Medicaid management information systems of the two states. Enrollment files were used to determine the age, sex, race, and category of enrollment of the patients, according to study month. Previous reports indicate that data from the Medicaid management information systems are highly reliable and valid for studying the prescribing of drugs or admission to nursing homes. ${ }^{12-16}$ Drug claims identified the product, number of units dispensed, patient, and date.

For every Medicaid resident of skilled-nursing and intermediatecare facilities, a monthly claim is submitted by the nursing home provider for basic services. Because the study population was already eligible for Medicaid at the beginning of the study, any nursing home stay would automatically be reimbursed from the first month of residence; we thus avoided the problem of missing data during periods when patients must expend their resources in order to reach eligibility levels.

Since all the members of the study cohorts were eligible for both Medicare and Medicaid, Medicare was the primary payer for hospital services. The Medicaid management information systems contain data on all such services for which Medicaid paid a deductible or coinsurance amount. For the first inpatient admission in each spell of illness, Medicaid pays a fixed deductible amount. We used the Medicaid data to determine inpatient hospital episodes by identifying each overnight service delivered at an acute care hospital for which the reimbursed amount was greater than or equal to the deductible amount for the current or previous year.

\section{Definition of the Study Groups}

The study groups represented a vulnerable, noninstitutionalized population of Medicaid patients over the age of 60 who were being treated for specific chronic illnesses at base line. Patients without Medicare coverage were excluded because in New Hampshire, patients enrolled only in Medicaid had limits on physicians' services and hospital days in addition to the cap on medications, whereas those enrolled in both Medicaid and Medicare ("crossover" patients) had stable coverage for these services. Patients were included in the study if they had 10 or more months of enrollment in Medicaid during the base-line year (July 1, 1980, to June 30, 1981); were 60 years of age or older and enrolled in Medicare by the start of the payment cap; were white (to control for the absence of nonwhite patients in the New Hampshire cohort); were living in the community at base line, with no nursing home claims during the 6 months before follow-up began; had an average of three or more prescriptions per month and at least one prescription per quarter during the base-line year; and used medication for one or more of five major chronic illnesses (diabetes, heart disease, chronic obstructive pulmonary disease and asthma, seizures, or conditions requiring the use of anticoagulants). Because outpatient diagnoses are often unreliable ${ }^{16}$ the regular receipt, before the cap, of medications commonly used to treat these illnesses served as markers for them. To eliminate occasional users of these drugs, we defined regular users as patients receiving eight or more prescriptions in any category of marker medications during the base-line year, and at least one per quarter.

A panel of geriatricians, internists, and clinical pharmacists identified specific classes of marker medications, including antianginal drugs, loop diuretic agents, antiarrhythmic agents, bronchodilators, inhaled steroids, insulin, anticoagulants, and anticonvulsant agents, hereafter referred to as the core drugs. Medications were chosen for study if their sudden withdrawal was liable to precipitate institutionalization. Agents were excluded if they were frequently used for nontargeted as well as targeted illnesses (e.g., beta-blockers are indicated for both hypertension and angina), had questionable efficacy, or were associated with less serious levels of illness. Thus, although they led to the exclusion of some patients with targeted illnesses, the strict criteria for regular drug use served to increase the base-line comparability of the study and comparison cohorts.

\section{Regular Use of Other Medications}

In addition to the core drugs, we also identified 21 other classes of drugs commonly used to treat chronic health problems. These included other agents to treat cardiovascular diseases (diuretic agents, beta-blockers, other antihypertensive drugs, and potassium supplements); oral hypoglycemic agents and diabetes-testing supplies; psychoactive medications (anxiolytic, hypnotic, antipsychotic, and antidepressant drugs); nonsteroidal antiinflammatory agents, analgesics with addictive potential, and those used to treat migraine; oral steroids; and medications to treat ulcers, thyroid disorders, glaucoma, parkinsonism, gout, and chronic diarrhea. As a measure of base-line comorbidity, we counted the number of these 26 classes of drugs for which each member of the study groups received eight or more prescriptions in the base-line year (Table 1).

\section{Standardization of Use of Study Medications}

To track drug use for the different study medications, we used base-line data on the entire Medicaid populations of both states to create an index of standardized monthly doses for each of the core medications. One standard dose equaled the median number of milligrams of active ingredient per month received by all the patients who filed a claim for each study drug.

\section{Statistical Analysis}

Using survival analysis, we measured the rate of admission to hospitals and nursing homes in New Hampshire and New Jersey during three periods: base line (April 1981 to August 1981), the cap (September 1981 to July 1982), and after the cap (August 1982 to June 1983). ${ }^{17,18}$ We also calculated the relative risks of institutional-

Table 1. Base-Line Characteristics of the Study and Comparison Cohorts.

\begin{tabular}{|c|c|c|}
\hline CHARACTERISTIC & $\begin{array}{c}\text { New HaMpSHIRE } \\
\text { STUDY COHORT } \\
(\mathrm{N}=411)\end{array}$ & $\begin{array}{c}\text { NEW JERSEY } \\
\text { COMPARISON } \\
\text { COHORT } \\
(\mathrm{N}=1375)\end{array}$ \\
\hline
\end{tabular}

\begin{tabular}{lrr} 
& \multicolumn{2}{c}{ percent } \\
Age (yr) & & \\
$60-69$ & 27 & 21 \\
$70-79$ & 43 & 46 \\
$\geqslant 80$ & 30 & 33 \\
Female sex & 80 & 80 \\
Regular use of core & & \\
$\quad$ medications & 77 & 86 \\
Cardiac & 19 & 15 \\
COPD and asthma* & 16 & 9 \\
Insulin & 6 & 7 \\
Anticonvulsants & 1 & 2 \\
Anticoagulants & & \\
Number of study medications & & 12 \\
$\quad$ used regularly $\dagger$ & 16 & 32 \\
1 & 36 & 28 \\
2 & 30 & 27 \\
3 & 18 & 23 \\
$\geqslant 4$ & 25 & \\
$\geqslant 1$ Inpatient episodes during & & \\
6 mo before cap & &
\end{tabular}

*COPD denotes chronic obstructive pulmonary disease.

†The core medications plus the 21 other classes of drugs commonly used to treat chronic health problems. 
ization and 95 percent two-sided confidence intervals in the study groups. ${ }^{19}$ We used segmented time-series regression models to estimate changes in drug use, including a constant term, a linear time trend, and terms to estimate changes in the mean level of use of core drugs during an "anticipatory" precap month (August 1981) and during the cap and copayment periods."

\section{Results}

\section{Background Characteristics of the Study Groups}

The base-line demographic characteristics and rates of drug use were similar in the New Hampshire and New Jersey groups (Table 1). The high proportion of women in both cohorts ( 80 percent) reflects the predominance of women in frail, elderly populations. In the year before the cap policy was instituted, approximately four out of five patients in both cohorts were regular recipients of core medications indicated for heart disease; rates of regular use of medications for chronic obstructive pulmonary disease and asthma, diabetes, and seizures were all similar, as were rates of use of anticoagulant agents. The total number of classes of drugs taken regularly was slightly higher in the comparison cohort; we controlled for the potential effects of this difference through the stratified analyses reported below. Although patient-specific data on income were unavailable, both cohorts were very poor, with incomes substantially below federal poverty levels; at the time of the study, the monthly income of elderly recipients of supplemental security income who lived alone was about $\$ 350$ in both states. ${ }^{20}$ During the follow-up period, similar proportions of patients (35 percent in New Hampshire and 28 percent in New Jersey) died or left the Medicaid program for other reasons.

\section{Changes in the Use of Study Medications}

During the base-line year the median number of standardized monthly doses of core drugs per month was stable at 2.8 in New Hampshire and 2.3 in New Jersey. There was no change in the use of these agents in New Jersey during the study period. In New Hampshire, however, the time series of drug use dropped by 35 percent, to 1.9 standardized monthly doses per patient per month after the cap was instituted (two-sided $\mathrm{P}<0.001$ ).
After the cap was replaced by the $\$ 1$ copayment, these rates rose almost to base-line levels.

\section{Effects on Nursing Home Admissions}

The most clearly observable effect of the payment cap in New Hampshire was an increase in nursing home admissions (Fig. 1). The proportions of patients entering nursing homes were similar in the study groups before the cap: 2.3 percent in New Hampshire and 2.1 percent in New Jersey. After the institution of the cap, there was a marked separation of the two survival curves showing the probability of remaining in the community; by the end of the 11-month cap

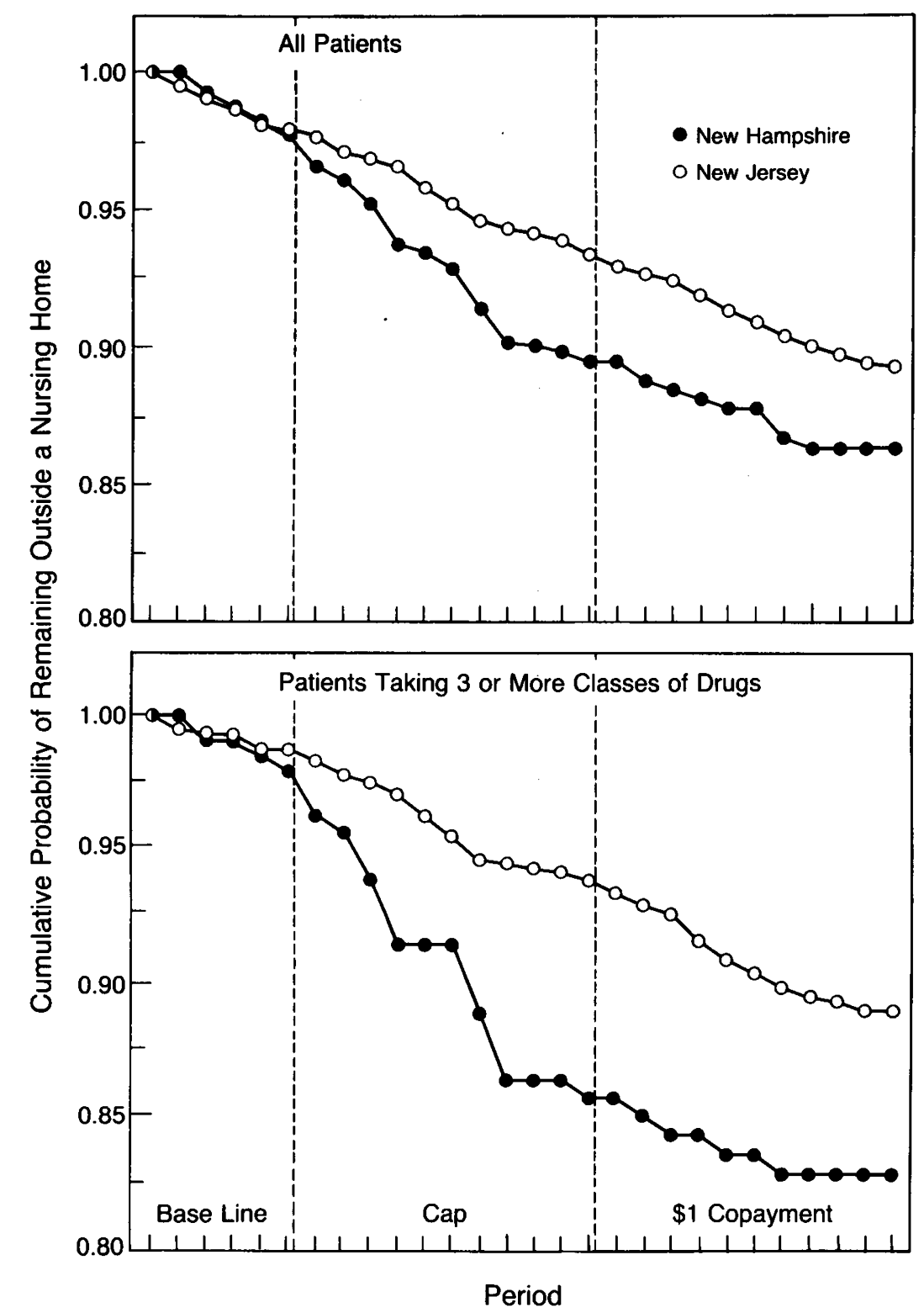

Figure 1. Cumulative Probability of Remaining outside a Nursing Home. The top panel shows the curves for all patients in the New Hampshire $(n=411)$ and New Jersey $(n=1375)$ groups. The bottom panel shows the curves for patients who regularly used drugs from three or more classes at base line $(n=198$ for New Hampshire and 762 for New Jersey). 
period, 10.6 percent of the New Hampshire patients and 6.6 percent of the New Jersey patients had been admitted to nursing homes. The difference between the two survival curves during this period was significant (two-sided $P=0.006$ ), and the relative risk of admission associated with the cap was 1.8 (95 percent confidence interval, 1.2 to 2.6 ). After the cap policy was discontinued, the use of core drugs returned almost to precap levels and the excess risk of new admissions to nursing homes ceased, as evidenced by the approximately parallel curves.

Further analyses were stratified according to the proxy variable for comorbidity (the regular use of 3 or more of the 26 classes of drugs). Again, the rates of nursing home admission in the two states were similar before the cap began and after it was replaced with the $\$ 1$ copayment (Fig. 1). During the period of the cap, however, the excess risk of admission to a nursing home was even greater for these sicker patients in the study cohort, more than double the rate in the comparison cohort (relative risk $=2.2$; 95 percent confidence interval, 1.2 to 4.1 ; two-sided $P=0.0004)$. By the end of the cap period, an estimated 14.4 percent of New Hampshire patients regularly taking drugs from three or more classes had entered nursing homes, as compared with only 6.2 percent of such patients in New Jersey. For the patients taking drugs from fewer than 3 of the 26 drug classes there was no significant difference between the study and comparison cohorts, indicating that the cap's adverse effect was most pronounced for the patients who were most disabled.

We next investigated whether this loss of independence tended to be permanent or temporary. Figure 2 shows trends in the proportions of patients residing in nursing homes in the two study groups. All the patients were included in this analysis until they died or became permanently ineligible. The data indicate that nursing home stays were not short-term. After the cap was instituted, there was a steady rise in the proportion of New Hampshire patients in nursing homes that persisted until the end of the cap period. By then, 7.7

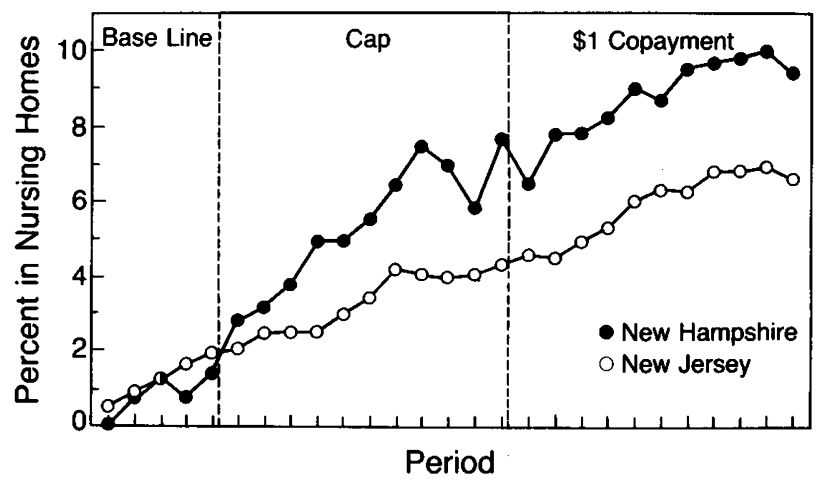

Figure 2. Monthly Proportions of Study Patients Residing in Nursing Homes.

The curves include all New Hampshire $(n=411)$ and New Jersey $(n=1375)$ patients.

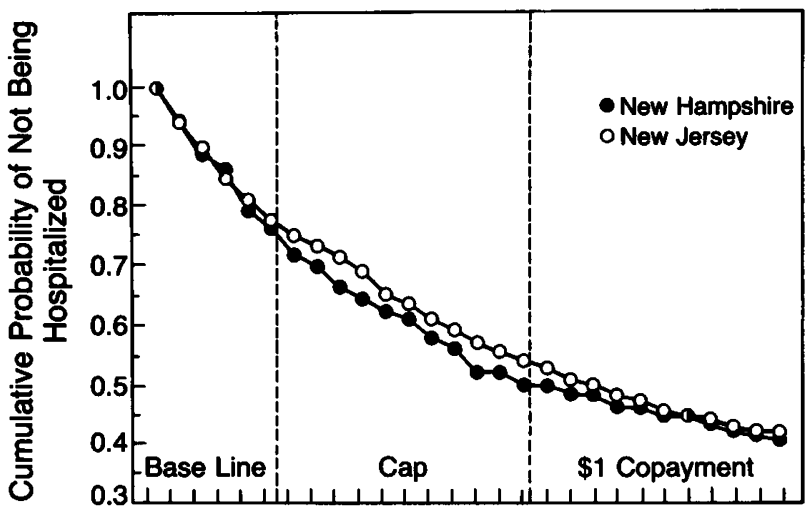

Period

Figure 3. Cumulative Probability of Not Being Hospitalized. The curves include the New Hampshire $(n=198)$ and New Jersey $(n=762)$ patients who regularly used drugs from three or more classes at base line.

percent of the 325 remaining New Hampshire patients were institutionalized, as compared with 4.4 percent of the 1147 New Jersey patients, even though the time series was approximately parallel before initiation of the cap and after its abandonment.

We also calculated the distribution of lengths of stay among the New Hampshire patients who entered nursing homes $(n=46)$. Among the 37 patients who entered nursing homes just before or during the period of the cap (for whom 12 or more months of follow-up were available until the end of observation), 32 percent stayed for 6 months or less and 57 percent had stayed for 1 year or more; 90 percent of the long-term residents were still in nursing homes during the final month of observation.

\section{Effects on Hospital Admissions}

Analyses of time to first inpatient hospital episode were similarly stratified according to the number of classes of drugs the patients took regularly. Patients who regularly used drugs from three or more classes had comparable rates of hospitalization before the cap was instituted (Fig. 3). After the introduction of the cap, there was a moderate trend toward increased hospitalization among the New Hampshire patients that did not reach statistical significance (relative risk $=$ 1.2; 95 percent confidence interval, 0.8 to 1.6 ); this trend disappeared when the cap was replaced with the $\$ 1$ copayment policy (Fig. 3). No increased risk of hospitalization was found in the patients who used drugs from fewer than three classes before the cap.

\section{Discussion}

Although quasi-experimental evaluations of policy changes can never provide ironclad evidence of causeand-effect relations, our results provide strong indications of a direct relation between the introduction of a three-drug reimbursement limit, a resulting reduction in the use of medications, and an approximate doubling of the rate of nursing home admissions among 
chronically ill elderly patients. Rates of admission to nursing homes among the study and comparison cohorts were similar before the cap was instituted, diverged soon after its introduction, when the use of medications declined, and once again became similar after the cap was abandoned. These effects were concentrated among patients who regularly used three or more study medications, indicating heightened vulnerability among patients with more than one chronic illness. A separate, ongoing analysis in New Hampshire also indicates an association between the rate of reduction in drug use due to the cap and the risk of institutionalization (data not shown).

Were nursing home admissions caused by declining health or by the desire to maintain the use of essential medications, because the three-drug limit did not apply in long-term care facilities? Since admission records were not available for this study, we could not distinguish between these two mechanisms of effect. The increase in nursing home admissions among the patients at highest risk suggests that the loss of medications could have exacerbated preexisting medical problems. However, because patients are often admitted to nursing homes without earlier hospitalization, ${ }^{21}$ and given case reports by New Hampshire Legal Assistance of several patients who were transferred to nursing homes to avoid the policy's effect, the cap probably precipitated nursing home admissions for financial reasons as well. Regardless of which mechanism explained the excess admissions, the economic impact of preventable institutionalization and its effects on quality of life are severe.

Although we observed a slight trend toward increased hospitalization during the period of the cap, the absence of a significant effect on rates of hospitalization deserves comment. Increases in the rate of hospitalization may have been too low to be measured against the high background rate in a chronically ill population. In addition, the measure used (time to first hospital episode) is insensitive to changes in the rates of repeated events; we unfortunately did not have access to data from the primary payer for hospital services, Medicare, which would have allowed time-series analyses of all admissions.

The study and comparison cohorts were well matched at base line for patterns of drug use, sex, and race, as well as nursing home and hospital use. The New Jersey cohort was slightly older and received more regular medications than the New Hampshire group, but this would be expected to reduce observed differences in outcomes. All the patients received more than 36 prescriptions in the base-line year, a rate of medication use strongly associated with fair-to-poor health in an earlier national study of Medicare beneficiaries. ${ }^{22}$ The increase in the rate of entry into nursing homes immediately after the initiation of the cap makes it less likely that differences in the patients' characteristics were responsible for these effects.

It is unlikely that other changes in policy influenced the observed changes in the rates of institutionalization. A potential confounder would have had to begin at the initiation of the cap and end at its termination, which is improbable. Since all the study patients were eligible for Medicare, they were exempt from the limits on hospital and physicians' services imposed on. non-Medicare patients in New Hampshire during the cap period. Changes in the supply of beds might influence the rate of admission to nursing homes. ${ }^{23}$ However, the supply of nursing home beds per 1000 elderly people in New Hampshire actually declined by 3.5 percent from 1981 to 1982 , the period during which we observed increases in the rates of admission as compared with those in New Jersey. ${ }^{23}$

Previous studies have indicated that the New Jersey diagnosis-related-group program initiated in 1980 probably caused a slight decline in length of stay and a small increase of 0.8 percent per year in hospital admission rates. ${ }^{24}$ The program, if it had any effect at all, would thus have shortened the time to first hospital admission slightly in the comparison cohort, resulting in a smaller relative difference between the two cohorts.

At present, about one fourth of state Medicaid programs have limits on drug reimbursement in effect. Our findings raise questions about the clinical and economic wisdom of such policies. Our best estimate of the excess person-months of nursing home use in the study cohort equals the difference between the proportions of the two study groups residing in nursing homes each month. During the 22-month observation period after the cap was instituted, this excess was estimated to be 174 person-months. Given New Hampshire Medicaid's daily reimbursement rate of $\$ 59$ in fiscal year 1982-1983 (the average of the rates for skilled-nursing facilities and intermediate-care facilities) ${ }^{25}$ these excess months in nursing homes cost $\$ 310,745$. This underestimates the true cost, since it does not include other incremental expenses (e.g., physicians' services) and it assumes no months in nursing homes beyond the observation period. Additional increases in hospital and nursing home admissions in other vulnerable populations that we did not study (e.g., the chronically mentally ill) could raise such unintended costs well over the estimated statewide savings of $\$ 300,000$ to $\$ 400,000$ achieved by the cap. ${ }^{.1}$

Changes in health care reimbursement policies have probably had sizable effects on elderly and low-income patients over the past decade, but objective data on their effects on quality of care are extremely limited. The challenge for researchers and policy makers is to discover which cost-containment methods are most efficient in reducing ineffective care while preserving access to forms of medical technology that benefit both individual patients and society as a whole.

We are indebted to Dan Gilden, director of JEN Associates, for statistical and data processing support; to Elin Griesbach for the coding and graphic presentation of data; to Jerry Gurwitz, M.D., and John Foley, Pharm.D., for excellent clinical advice; to Dr. Stephen Lagakos for important insights into the structuring of the statistical analysis; to the officers and staff of the New Hampshire and New Jersey Medicaid programs who supplied the data; and to Laura Goldberg for assistance in the preparation of the manuscript. 


\section{REFERENCES}

1. Fitzgerald JF, Fagan JF, Tierney WM, Dittus RS. Changing patterns of hip fracture care before and after implementation of prospective payment system. JAMA 1987;258:218-21.

2. Lurie N, Ward NB, Shapiro MF, Brook RH. Termination from Medi-Cal does it affect health? N Engl J Med 1984;311:480-4.

3. Holahan JF, Cohen JW. Medicaid: the trade-off between cost containment and access to care. Washington, D.C.: Urban Institute Press, 1986.

4. Veterans Administration Cooperative Study Group on Antihypertensive Agents. Effects of treatment on morbidity in hypertension. JAMA 1967 202:1028-34.

5. Idem. Effects of treatment on morbidity in hypertension. JAMA 1970; 213:1143-52.

6. The Norwegian Multicenter Study Group. Timolol-induced reduction in mortality and reinfarction in patients surviving acute myocardial infarction. N Engl J Med 1981;304:801-7.

7. Levy M, Mermelstein L, Hemo D. Medical admissions due to noncompliance with drug therapy. Int J Clin Pharmacol Ther Toxicol 1982;20:6004.

8. Stason WB, Weinstein MC. Allocation of resources to manage hypertension. N Engl J Med 1977;296:732-9.

9. Strandberg LR. Drugs as a reason for nursing home admissions. Am Health Care Assoc J 1984;10(4):20-3.

10. Maronde RF, Chan LS, Larsen FJ, Strandberg LR, Laventurier MF, Sullivan SR. Underutilization of antihypertensive drugs and associated hospitalization. Med Care 1989;27:1159-66.

11. Soumerai SB, Avorn J, Ross-Degnan D, Gortmaker S. Payment restriction for prescription drugs under Medicaid: effects on therapy, cost, and equity. N Engl J Med 1987;317:550-6.

12. Ray WA, Federspiel CF, Baugh DK, Dodds S. Interstate variation in elderly Medicaid nursing home populations: comparison of resident characteristics and medical care utilization. Med Care 1987;25:738-52.

13. Federspiel CF, Ray WA, Schaffner W. Medicaid records as a valid data source: the Tennessee experience. Med Care 1976;14:166-72.
14. Schaffner W, Ray WA, Federspiel CF, Miller WO. Improving antibiotic prescribing in office practice: a controlled trial of three educational methods. JAMA 1983;250:1728-32.

15. Avorn J, Soumerai SB. Improving drug-therapy decisions through educational outreach: a randomized controlled trial of academically-based "detailing." N Engl J Med 1983;308:1457-63.

16. Department of Commerce, National Technical Information Service. Medicaid data as a source for postmarketing surveillance information. Vol. 1 Technical report. Research Triangle Park, N.C.: Research Triangle Institute, 1984.

17. Kaplan EL, Meier P. Nonparametric estimation from incomplete observations. J Am Stat Assoc 1958;53:457-81.

18. Mantel N. Evaluation of survival data and two new rank order statistics arising in its consideration. Cancer Chemother Rep 1966;50:163-70.

19. Cox DR. Regression models and life-tables. J R Stat Soc [B] 1972;34:187

20. Health Care Financing Administration, Office of the Actuary. Health care financing program statistics: analysis of state Medicaid program characteristics, 1984. Washington, D.C.: Government Printing Office, 1985. (HCFA publication no. 03204.)

21. Ray WA, Federspiel CF, Baugh DK, Dodds S. Experience of a Medicaid nursing home entry cohort. Health Care Financ Rev 1989;10(4):51-63.

22. Public Health Service, National Center for Health Services Research and Health Care Technology Assessment. Prescribed medicines: a summary of the use and expenditures by Medicare beneficiaries. Research findings 3. Rockville, Md.: Department of Health and Human Services, 1989. (DHHS publication no. (PHS) 89-3448.)

23. Harrington C, Swan JH, Grant LA. Nursing home bed capacity in the States, 1978-86. Health Care Financ Rev 1988;9(4):81-97.

24. Hsiao WC, Sapolsky HM, Dunn DL, Weiner SL. Lessons of the New Jersey DRG payment system. Health Aff (Millwood) 1986;5:32-45.

25. Health Care Financing Administration, Office of the Actuary. Health care financing program statistics: analysis of state Medicaid program characteristics, 1986. Washington, D.C.: Government Printing Office, 1987:87-90. (HCFA publication no. 03249.) 